\title{
Classification of the Nickel-Like Silver Spectrum (AgXX) from a Fast Capillary Discharge Plasma
}

\author{
A. Rahman ${ }^{1}$, J. J. Rocca ${ }^{1,2, *}$ and J.-F. Wyart ${ }^{3, * *}$ \\ ${ }^{1}$ National Science Foundation Engineering Research Center for Extreme Ultraviolet Science and Technology and Department of Electrical and \\ Computer Engineering, Colorado State University. \\ ${ }^{2}$ Department of Physics, Colorado State University, Fort Collins, CO 80523, USA \\ ${ }^{3}$ Laboratoire Aimé Cotton, CNRS (UPR 3321), Centre Universitaire, 91405-Orsay, France
}

Received September 22, 2003; accepted February 2, 2004

PACS Ref: $32.30,32.70,42.55$.

\begin{abstract}
A study of the Ni-like silver (AgXX) spectra in the $13.7-20.5 \mathrm{~nm}$ wavelength region using a plasma generated by a fast high power capillary discharge is reported. Forty-three $\mathrm{AgXX}$ transitions have been identified with the assistance of calculations performed using the Slater-Condon method with generalized least-squares fits of the energy parameters. The average difference between the measured transition wavelengths and the theoretical values is $0.0026 \mathrm{~nm}$.
\end{abstract}

\section{Introduction}

Capillary discharge excitation has proven to be an efficient method to create very compact lasers in the 46.9-60.8 nm spectral region using Neon-like ions [1-3]. Several applications demand lasers at even shorter wavelengths. In particular, the metrology associated with extreme ultraviolet lithography for the fabrication of the future generations of integrated circuits motivates the development of lasers emitting at wavelengths in the vicinity of $13.5 \mathrm{~nm}$ [4]. Lasing at 13.9 and $13.2 \mathrm{~nm}$ in the $3 \mathrm{~d}^{9} 4 \mathrm{~d}^{1} \mathrm{~S}_{0}-3 \mathrm{~d}^{9} 4 \mathrm{p}^{1} \mathrm{P}_{1}$ transitions of nickel-like silver [5-10] and cadmium [8] respectively has been observed in laser-created plasmas. Further, lasing was observed on the $4 \mathrm{f}^{1} \mathrm{P}_{1}-4 \mathrm{~d}{ }^{1} \mathrm{P}_{1}$ transition of $\mathrm{AgXX}$ at $16.05 \mathrm{~nm}$ [10]. The further development of practical lasers operating in this wavelength region generates significant interest in the spectra of these $\mathrm{Ni}$ like ions. Recently, a detailed spectroscopic study of $\mathrm{Ni}$ like $\mathrm{Cd}$ has been reported utilizing a capillary discharge plasma [11]. Numerous newly identified Ni-like cadmium transitions were observed and classified in the $12.7-18.4 \mathrm{~nm}$ wavelength region in a cadmium plasma excited by such a discharge.

Herein we report the use of a similar discharge in silver vapor to study the spectra of Ni-like silver in the spectral region between 12.7 and $20.5 \mathrm{~nm}$. A highly ionized $\mathrm{Ag}$ plasma was obtained with fast capillary discharge excitation of a silver vapor filled capillary channel with discharge current pulses up to $200 \mathrm{kA}$ peak amplitude and a current rate increase of approximately $1.5 \times 10^{13} \mathrm{~A} / \mathrm{s}$. Previous work in laser-created plasmas [12] has identified five $\mathrm{AgXX}$ lines in the $17.0-19.0 \mathrm{~nm}$ spectral region as $4 \mathrm{p}-4 \mathrm{~d}$ transitions, in addition to 18 lines of the $3 d^{9} 4 s-3 d^{9} 4 p$ array from 24.8 to $31.8 \mathrm{~nm}$. In the present spectra, all previously reported $4 d-4 p$ and $4 d-4 f$ transitions of AgXIX [13] and

\footnotetext{
* e-mail: rocca@engr.colostate.edu

** e-mail: Jean-Francois.Wyart@lac.u-psud.fr
}

AgXX were strong emission lines and this was an incentive to extend the classification to weaker lines.

The plasma generation technique and the set-up utilized in the acquisition of the spectra are discussed in the next section. Section 3 discusses the theoretical computation and the line assignments.

\section{Experimental set-up}

The highly ionized silver plasmas of interest were generated by rapid electromagnetic compression of a silver vapor plasma column in a capillary channel. In these types of plasmas the contrast between the line and continuum spectra can be significantly larger than in laser created plasma, facilitating the classification of bound-bound atomic transitions. The silver vapor was created by heating and vaporizing a silver electrode with a current pulse. The metal vapor produced by this room-temperature metal vapor gun was injected through a hollow electrode into a $5 \mathrm{~mm}$ diameter, $4 \mathrm{~cm}$ long channel drilled into a polyacethal rod. The silver vapor injected into the channel was preionized using a moderate current pulse and was subsequently compressed and heated using a fast high current pulse of $160-200 \mathrm{kA}$ peak amplitude and $\sim 12-15 \mathrm{~ns}$ risetime. The high current pulse was produced using a three stage pulse-compression system consisting of a conventional eight-stage Marx generator, followed by a $26 \mathrm{nF}$ cylindrical water dielectric capacitor and a radial water-dielectric Blumlein transmission line [14]. The Marx generator was operated at an erected voltage of $\sim 650 \mathrm{kV}$ to charge the water dielectric capacitor that in turn was discharged through a self-breaking spark-gap pressurized with $\mathrm{SF}_{6}$ gas to pulse charge the transmission line. The Blumlein transmission line was discharged through the capillary channel located on its axis triggering an array of seven synchronously triggered spark-gaps. Each stage of pulse compression enables the generation of current pulses of increasingly shorter risetimes, allowing the creation of very fast current risetimes with a current increase rate that exceeds $1.5 \times 10^{13} \mathrm{~A} / \mathrm{s}$. The Lorentz force associated with the current pulse rapidly compresses and heats the plasma, generating a narrow plasma column on axis, which reaches the Ni-like stage of ionization. Maximum soft X-ray emission occurs when the column pinches on axis. Pinhole camera measurements of cadmium plasma columns excited under similar discharge conditions show that at this time 

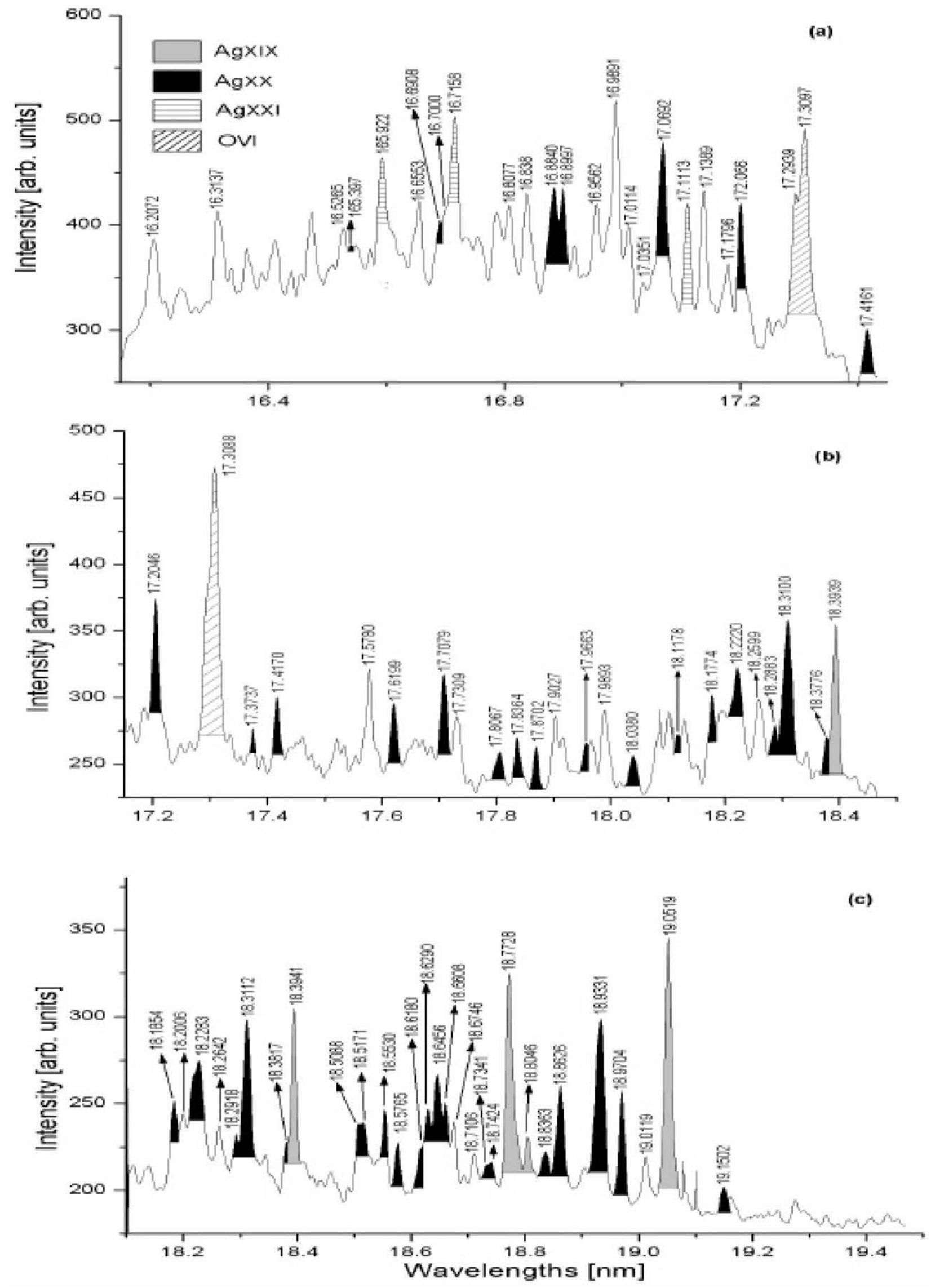

Fig. 1. (a)-(c) Spectra of capillary discharge silver plasma for the 16.2-19.4 nm wavelength region. Each spectrum corresponds to a single discharge shot and was acquired with a time resolution of about $5 \mathrm{~ns}$. The capillary diameter was $5 \mathrm{~mm}$ and the discharge current pulse had a peak amplitude of $167 \mathrm{kA}, 167 \mathrm{kA}$ and $164 \mathrm{kA}$ respectively. Each spectral line is identified with the experimental wavelength corresponding to that particular discharge shot. The difference in wavelength of the lines appearing in the overlapping regions are illustrative of the error associated with the measurements. Notice that the experimental wavelengths listed in Table II are the result of averaging several spectra. Some of the weak lines listed in Table II which do not appear clearly in these spectra were classified based on their identification in the spectra corresponding to other discharge shots. 
Table I Energy levels of $\operatorname{AgXX}$. Levels are designated in the $\left(J_{1}, j_{2}\right)$ coupling scheme with $J$ and $N$ index numbering from the lowest level in its $J$-value for the configuration. The ( $J_{1}$, $\left.j_{2}\right)$ purity in $\%$ is followed by SL leading components and purities. Energy values are in $\mathrm{cm}^{-1}$.

\begin{tabular}{|c|c|c|c|c|c|c|c|}
\hline Config. & Multiplet & $J$ & $N^{\text {th }}$ & $\%$ & $S L \%$ & $E_{\text {exp }}$ & $E_{\mathrm{GLS}}$ \\
\hline $3 d^{10}$ & & 0 & 1 & & ${ }^{1} \mathrm{~S} 100$ & 0 & 0 \\
\hline \multirow[t]{4}{*}{$3 d^{9} 4 s$} & $(5 / 2,1 / 2)$ & 3 & 1 & 100 & ${ }^{3} \mathrm{D} 100$ & 2807885 & 2807855 \\
\hline & $(5 / 2,1 / 2)$ & 2 & 1 & 99 & ${ }^{3} \mathrm{D} 51$ & 2814345 & 2814304 \\
\hline & $(3 / 2,1 / 2)$ & 1 & 1 & 100 & ${ }^{3} \mathrm{D} 100$ & 2859060 & 2859074 \\
\hline & $(3 / 2,1 / 2)$ & 2 & 2 & 99 & ${ }^{1} \mathrm{D} 51$ & 2864395 & 2864451 \\
\hline \multirow[t]{12}{*}{$3 d^{9} 4 p$} & $(5 / 2,1 / 2)$ & 2 & 1 & 96 & ${ }^{3} \mathrm{P} 67$ & 3122417 & 3122540 \\
\hline & $(5 / 2,1 / 2)$ & 3 & 1 & 99 & ${ }^{3} \mathrm{~F} 50$ & 3129393 & 3129309 \\
\hline & $(3 / 2,1 / 2)$ & 2 & 2 & 93 & ${ }^{3} \mathrm{~F} 85$ & 3175562 & 3175607 \\
\hline & $(3 / 2,1 / 2)$ & 1 & 1 & 71 & ${ }^{3} \mathrm{P} 58$ & 3181814 & 3181734 \\
\hline & $(5 / 2,3 / 2)$ & 4 & 1 & 100 & ${ }^{3} \mathrm{~F} 100$ & 3191211 & 3191162 \\
\hline & $(5 / 2,3 / 2)$ & 2 & 2 & 90 & ${ }^{1} \mathrm{D} 62$ & 3201870 & 3201870 \\
\hline & $(5 / 2,3 / 2)$ & 1 & 2 & 69 & ${ }^{1} \mathrm{P} 82$ & 3206188 & 3206250 \\
\hline & $(5 / 2,3 / 2)$ & 3 & 2 & 99 & ${ }^{3} \mathrm{D} 74$ & 3209891 & 3209772 \\
\hline & $(3 / 2,3 / 2)$ & 0 & 1 & 100 & ${ }^{3} \mathrm{P} 100$ & 3229410 & 3229433 \\
\hline & $(3 / 2,3 / 2)$ & 3 & 3 & 100 & ${ }^{3} \mathrm{~F} 49$ & 3248295 & 3248421 \\
\hline & $(3 / 2,3 / 2)$ & 1 & 3 & 92 & ${ }^{3} \mathrm{D} 59$ & 3251230 & 3251044 \\
\hline & $(3 / 2,3 / 2)$ & 2 & 4 & 98 & ${ }^{3} \mathrm{D} 57$ & 3258589 & 3258728 \\
\hline \multirow[t]{18}{*}{$3 d^{9} 4 d$} & $(5 / 2,3 / 2)$ & 1 & 1 & 69 & ${ }^{3} \mathrm{~S} 79$ & 3687150 & 3687297 \\
\hline & $(5 / 2,3 / 2)$ & 4 & 1 & 98 & ${ }^{3} \mathrm{D} 57$ & 3710770 & 3710662 \\
\hline & $(5 / 2,3 / 2)$ & 2 & 1 & 87 & ${ }^{3} \mathrm{P} 51$ & 3714000 & 3714179 \\
\hline & $(5 / 2,3 / 2)$ & 3 & 1 & 89 & ${ }^{3} \mathrm{D} 44$ & 3721590 & 3721435 \\
\hline & $(5 / 2,5 / 2)$ & 1 & 2 & 71 & ${ }^{1} \mathrm{P} 51$ & 3719060 & 3718862 \\
\hline & $(5 / 2,5 / 2)$ & 5 & 1 & 100 & ${ }^{3} \mathrm{G} 100$ & 3719430 & 3719454 \\
\hline & $(5 / 2,5 / 2)$ & 3 & 2 & 88 & ${ }^{3} \mathrm{D} 39$ & 3732080 & 3732215 \\
\hline & $(5 / 2,5 / 2)$ & 2 & 2 & 83 & ${ }^{1}$ D 39 & 3737110 & 3736977 \\
\hline & $(5 / 2,5 / 2)$ & 4 & 2 & 98 & ${ }^{3} \mathrm{~F} 78$ & 3738070 & 3738186 \\
\hline & $(5 / 2,5 / 2)$ & 0 & 1 & 50 & ${ }^{3} \mathrm{P} 99$ & 3743390 & 3743026 \\
\hline & $(3 / 2,3 / 2)$ & 1 & 3 & 69 & ${ }^{1} \mathrm{P} 47$ & 3757490 & 3757758 \\
\hline & $(3 / 2,3 / 2)$ & 3 & 3 & 93 & ${ }^{3} \mathrm{G} 74$ & 3761440 & 3761250 \\
\hline & $(3 / 2,3 / 2)$ & 2 & 3 & 96 & ${ }^{3} \mathrm{~F} 71$ & 3780240 & 3780364 \\
\hline & $(3 / 2,3 / 2)$ & 0 & 2 & 51 & ${ }^{1} \mathrm{~S} 99$ & 3926590 & 3926657 \\
\hline & $(3 / 2,5 / 2)$ & 1 & 4 & 68 & ${ }^{3} \mathrm{D} 56$ & 3769630 & 3769578 \\
\hline & $(3 / 2,5 / 2)$ & 4 & 3 & 98 & ${ }^{1} \mathrm{G} 41$ & 3777140 & 3777078 \\
\hline & $(3 / 2,5 / 2)$ & 2 & 4 & 93 & ${ }^{3} \mathrm{D} 41$ & 3783160 & 3783151 \\
\hline & $(3 / 2,5 / 2)$ & 3 & 4 & 97 & ${ }^{3} \mathrm{~F} 53$ & 3788660 & 3788801 \\
\hline \multirow[t]{20}{*}{$3 \mathrm{~d} 94 \mathrm{f}$} & $(5 / 2,5 / 2)$ & 0 & 1 & 100 & ${ }^{3} \mathrm{P} 100$ & & 4237753 \\
\hline & $(5 / 2,5 / 2)$ & 1 & 1 & 78 & ${ }^{3} \mathrm{P} 90$ & 4242500 & 4242766 \\
\hline & $(5 / 2,5 / 2)$ & 2 & 1 & 69 & ${ }^{3} \mathrm{P} 64$ & & 4250992 \\
\hline & $(5 / 2,5 / 2)$ & 5 & 1 & 97 & ${ }^{3} \mathrm{H} 55$ & 4257030 & 4257022 \\
\hline & $(5 / 2,5 / 2)$ & 3 & 1 & 57 & ${ }^{3} \mathrm{D} 54$ & 4265930 & 4266009 \\
\hline & $(5 / 2,5 / 2)$ & 4 & 1 & 70 & ${ }^{3} \mathrm{~F} 77$ & 4270140 & 4269009 \\
\hline & $(5 / 2,7 / 2)$ & 6 & 1 & 100 & ${ }^{3} \mathrm{H} 100$ & 4255340 & 4254974 \\
\hline & $(5 / 2,7 / 2)$ & 2 & 2 & 74 & ${ }^{1} \mathrm{D} 40$ & & 4264980 \\
\hline & $(5 / 2,7 / 2)$ & 4 & 2 & 67 & ${ }^{1} \mathrm{G} 47$ & 4271600 & 4272036 \\
\hline & $(5 / 2,7 / 2)$ & 5 & 2 & 96 & ${ }^{3} \mathrm{G} 76$ & 4274400 & 4274068 \\
\hline & $(5 / 2,7 / 2)$ & 3 & 2 & 56 & ${ }^{1} \mathrm{~F} 48$ & 4276550 & 4276293 \\
\hline & $(5 / 2,7 / 2)$ & 1 & 2 & 48 & ${ }^{3} \mathrm{D} 85$ & 4283940 & 4283578 \\
\hline & $(3 / 2,7 / 2)$ & 2 & 3 & 85 & ${ }^{3}$ D 37 & & 4304534 \\
\hline & $(3 / 2,7 / 2)$ & 4 & 3 & 93 & ${ }^{3} \mathrm{H} 73$ & 4310260 & 4310013 \\
\hline & $(3 / 2,7 / 2)$ & 5 & 3 & 97 & ${ }^{3} \mathrm{H} 39$ & 4313940 & 4313746 \\
\hline & $(3 / 2,7 / 2)$ & 3 & 4 & 98 & ${ }^{3} \mathrm{G} 63$ & 4329060 & 4328895 \\
\hline & $(3 / 2,5 / 2)$ & 2 & 4 & 90 & ${ }^{3} \mathrm{~F} 63$ & & 4317844 \\
\hline & $(3 / 2,5 / 2)$ & 3 & 3 & 99 & ${ }^{3} \mathrm{~F} 41$ & 4322160 & 4322284 \\
\hline & $(3 / 2,5 / 2)$ & 4 & 4 & 95 & ${ }^{3} \mathrm{G} 45$ & 4326960 & 4327415 \\
\hline & $(3 / 2,5 / 2)$ & 1 & 3 & 66 & ${ }^{1} \mathrm{P} 93$ & 4381930 & 4382027 \\
\hline
\end{tabular}

the soft X-ray emitting region has a diameter of 250$350 \mu \mathrm{m}$. Shortly after, the soft X-ray emission decreases as the plasma column expands and rapidly cools [15].
Plasma radiation emitted through axial holes in the ground electrode and metal vapor gun was collected and focused onto the slit of a $2.217 \mathrm{~m}$ grazing incidence spectrograph using a gold-coated cylindrical mirror placed at a grazing angle of $85.8^{\circ}$. The radiation was dispersed by a 2400 lines/mm gold-coated grating mounted at an angle of incidence of $85.8^{\circ}$ along the perimeter of a Rowland circle. The first order diffracted beam was recorded by a two-dimensional array detector system. This detector consists of two micro-channel plates (MCP's) mounted in a chevron configuration, a fiber optics plate coated with phosphorous, and a $1024 \times 1024$ pixels CCD camera. The MCP's were gated with a resolution of $\sim 5 \mathrm{~ns}$ to allow the recording of spectra corresponding to different times of the plasma column evolution. Resolution of the instrument is limited by the $\mathrm{MCP} / \mathrm{CCD}$ detector. This detector offers lower resolution than photographic plate, however it has the advantage of allowing for single-shot time resolved spectra. Figure 1 shows typical spectra of capillary discharge silver plasma for the 16.2-19.4 nm wavelength region. Calibration of the spectral region between 12.80 $14.00 \mathrm{~nm}$ was performed using known transitions of OVI, OVII, ArVIII and FVI [16]. A second spectral region of interest, covering the wavelength range between 16.5 and $20.5 \mathrm{~nm}$ was calibrated using various known Argon transitions (ArIX through ArXIV) and OVI lines [16]. The calibration was verified by acquiring highly ionized silver spectra and comparing them with previously known lines of AgXIX and $\operatorname{AgXX}$. The measured values of AgXIX lines averaged over several shots were found to deviate by less than $0.004 \mathrm{~nm}$ from those previously reported in the literature [13]. The maximum deviation between the $\mathrm{AgXX}$ lines reported in the literature [12] and the values measured in the present experiment was found to be $0.013 \mathrm{~nm}$. From these comparisons, from the difference between the wavelength of other known lines and those obtained applying the calibration curve, and from shot to shot variations of the measured wavelengths, the error in the measurement of the transition wavelengths reported herein can be conservatively estimated at $0.01 \mathrm{~nm}$.

\section{Interpretation of the silver spectra}

The same theoretical methods previously used to classify lines from CdXXI [11] was used for AgXX. The advantages of the Generalized least-squares (GLS) techniques for improving the reliability of multicharged ions predicted energies in the framework of the Racah-Slater method had been stressed in Ref. [11] and will not be repeated. Isoelectronic constraints were applied to the scaling factors of radial parameters of the four excited configurations $3 \mathrm{~d}^{9} 4 l(l=\mathrm{s}, \mathrm{p}, \mathrm{d}, \mathrm{f})$. The scaling factor is the ratio of an 'adjustable' radial parameter to its ab initio (HFR) value, which is derived from the RCN, RCN2 codes by R. D. Cowan [17]. The experimental $4 \mathrm{~s}$ and $4 \mathrm{p}$ levels used in the GLS fits were those of [12] and earlier references. For $3 \mathrm{~d}^{9} 4 \mathrm{~d}$, the set of $E_{\text {exp }}$ values was extended from 228 values in [12] to 239 after inclusion of the new $\mathrm{AgXX}$ levels in the final fit. The predicted levels of $\mathrm{AgXX}$ are collected in Table I and are compared with energies derived from the classified lines of Table II. As for the case of CdXXI, the $\left(J_{1}, j_{2}\right)$ coupling is a better approximation than is $L S$ and 
Table II Classification of lines of Nickel-like AgXX. The first column shows the calculated wavelengths ( $\lambda_{\text {cal }}$ in $n m$ ) as they are derived from the "best" experimental values in Table I. The second and third column show the experimental wavelengths $\left(\lambda_{\exp }\right)$ and wavenumbers. Int is the measured relative intensity. The level designations imply the $J$-value and index $\mathrm{N}_{\text {th }}$ which numbers the levels from the lowest energy in the same J-value and configuration as used in [12]. The emission transition probability $\mathrm{gA}$ (in $10^{9} \mathrm{~s}^{-1}$ ) in length form is derived by means of Cowan codes for $E_{\mathrm{GLS}}$ level values with no C.I. effects included.

\begin{tabular}{|c|c|c|c|c|c|c|c|c|c|c|}
\hline$\lambda_{\text {cal }}(\mathrm{nm})$ & $\lambda_{\exp }(\mathrm{nm})$ & $\lambda\left(\mathrm{cm}^{-1}\right)$ & Int & $\mathrm{gA}$ & $\lambda_{\text {exp }}-\lambda_{\text {cal }}$ & $J_{0} N_{\text {th }}$ & $J_{\mathrm{e}} N_{\text {th }}$ & $E_{\text {odd }}$ & $E_{\text {even }}$ & Comment \\
\hline 13.4269 & 13.4250 & 744879 & 1 & 16 & -0.0019 & $4 p 11$ & $4 d 02$ & 3181814 & 3926590 & \\
\hline 13.8811 & 13.8830 & 720305 & 7 & 153 & 0.0011 & $4 \mathrm{p} 12$ & $4 d 02$ & 3206188 & 3926590 & \\
\hline 16.5377 & 16.5390 & 604617 & 2 & 198 & 0.0013 & 4 p 22 & $4 d 23$ & 3175562 & 3780240 & \\
\hline 16.5924 & 16.5919 & 602704 & 2 & 46 & -0.0005 & 4 p 31 & $4 d 32$ & 3129393 & 3732080 & S, AgXXI \\
\hline 16.6898 & 16.6898 & 599168 & 3 & 249 & 0.0000 & 4 p 21 & $4 d 31$ & 3122417 & 3721590 & \\
\hline 16.7105 & 16.7122 & 598365 & 3 & 100 & 0.0017 & $4 \mathrm{p} 11$ & $4 d 23$ & 3181814 & 3780240 & $\mathrm{~S}, \mathrm{AgXXI}$ \\
\hline 16.8863 & 16.8870 & 592171 & 4 & 286 & -0.0007 & 4 p 31 & $4 d 31$ & 3129393 & 3721590 & \\
\hline 16.9038 & 16.8995 & 591733 & 4 & 347 & -0.0043 & 4 p 21 & $4 d 21$ & 3122417 & 3714000 & \\
\hline 17.0684 & 17.0704 & 585809 & 5 & 517 & 0.0020 & 4 p 22 & $4 d 33$ & 3175562 & 3761440 & \\
\hline 17.1055 & 17.1088 & 584495 & 2 & 73 & 0.0033 & $4 p 31$ & $4 d 21$ & 3129393 & 3714000 & $\mathrm{~S}, \mathrm{AgXXI}$ \\
\hline 17.2005 & 17.2039 & 581264 & 6 & 797 & -0.0034 & 4 p 31 & $4 d 41$ & 3129393 & 3710770 & \\
\hline 17.3709 & 17.3752 & 575533 & 1 & 125 & 0.0043 & $4 \mathrm{p} 11$ & 4d 13 & 3181814 & 3757490 & \\
\hline 17.4200 & 17.4152 & 574211 & 3 & 94 & -0.0048 & $4 \mathrm{p} 12$ & $4 d 23$ & 3206188 & 3780240 & \\
\hline 17.6174 & 17.6213 & 567495 & 3 & 97 & 0.0039 & $4 d 33$ & 4f 34 & 3761440 & 4329060 & $\mathrm{~S}$ \\
\hline 17.7075 & 17.7074 & 564736 & 4 & 210 & -0.0001 & 4 p 21 & 4d 11 & 3122417 & 3687150 & \\
\hline 17.7029 & 17.7074 & 564736 & 4 & 99 & 0.0045 & $4 d 12$ & 4f 12 & 3719060 & 4283940 & S, AgXXI \\
\hline 17.8070 & 17.8070 & 561577 & 1 & 85 & 0.0000 & $4 \mathrm{p} 11$ & 4d 01 & 3181814 & 3743390 & Tentative, Blend \\
\hline 17.8079 & 17.8070 & 561577 & 1 & 28 & -0.0009 & 4 p 22 & $4 d 22$ & 3175562 & 3737110 & Tentative, Blend \\
\hline 17.8336 & 17.8377 & 560610 & 2 & 140 & 0.0041 & $4 d 41$ & 4f 42 & 3710770 & 4271600 & \\
\hline 17.8709 & 17.8688 & 559635 & 2 & 95 & -0.0021 & 4 p 23 & $4 d 33$ & 3201870 & 3761440 & \\
\hline 17.9689 & 17.9670 & 556576 & 1 & 78 & -0.0019 & 4 p 22 & $4 d 32$ & 3175562 & 3732080 & \\
\hline 18.0190 & 18.0216 & 554890 & $1 \mathrm{~b}$ & 161 & 0.0026 & $4 d 51$ & 4f 52 & 3719430 & 4274400 & \\
\hline 18.1182 & 18.1182 & 551931 & $2 b$ & 248 & 0.0000 & $4 d 21$ & 4f 31 & 3714000 & 4265930 & \\
\hline 18.1815 & 18.1773 & 550137 & 3 & 194 & -0.0042 & $4 d 31$ & 4f 42 & 3721590 & 4271600 & \\
\hline 18.2209 & 18.2205 & 548832 & $4 \mathrm{~b}$ & 747 & -0.0004 & $4 d 33$ & 4f 43 & 3761440 & 4310260 & Tentative, Blend \\
\hline 18.2209 & 18.2205 & 548832 & $4 \mathrm{~b}$ & 442 & -0.0004 & $4 d 23$ & 4f 34 & 3780240 & 4329060 & Tentative, Blend \\
\hline 18.2299 & 18.2205 & 548832 & $4 b$ & 315 & -0.0094 & $4 d 31$ & 4f 41 & 3721590 & 4270140 & Tentative, Blend \\
\hline 18.2862 & 18.2868 & 546849 & 2 & 219 & 0.0006 & $4 p 41$ & $4 d 42$ & 3191211 & 3738070 & \\
\hline 18.3092 & 18.3094 & 546174 & 5 & 902 & 0.0002 & $4 d 41$ & 4f 51 & 3710770 & 4257030 & \\
\hline 18.3665 & 18.3803 & 544040 & $1 \mathrm{~b}$ & 122 & 0.0138 & $4 d 32$ & 4f 32 & 3732080 & 4276550 & Tentative, Blend \\
\hline 18.3709 & 18.3803 & 544040 & $1 b$ & 227 & 0.0094 & $4 d 31$ & 4f 31 & 3721590 & 4265930 & Tentative, Blend \\
\hline 18.3942 & 18.3941 & 543653 & 5 & 521 & -0.0001 & $4 \mathrm{~d} 3 / 2$ & 4f $5 / 2$ & 892277 & 1435920 & AgXIX 18.3942 \\
\hline 18.5048 & 18.5088 & 540284 & $2 b$ & 60 & 0.0040 & $4 d 34$ & 4f 34 & 3788660 & 4329060 & Tentative, Blend \\
\hline 18.5060 & 18.5088 & 540284 & $2 b$ & 142 & 0.0028 & 4 p 33 & 4d 34 & 3248295 & 3788660 & Tentative, Blend \\
\hline 18.5110 & 18.5152 & 540097 & $2 b$ & 126 & 0.0042 & 4 p 01 & 4d 14 & 3229410 & 3769630 & \\
\hline 18.5350 & 18.5309 & 539639 & $1 b$ & 436 & 0.0041 & $4 d 32$ & 4f 42 & 3732080 & 4271600 & $\mathrm{q}$ \\
\hline 18.5378 & 18.5378 & 539438 & $1 b$ & 373 & 0.0000 & $4 d 22$ & 4f 32 & 3737110 & 4276550 & $\mathrm{q}$ \\
\hline 18.5530 & 18.5530 & 538996 & 2 & 450 & 0.0000 & $4 \mathrm{~d} 24$ & 4f 33 & 3783160 & 4322160 & \\
\hline 18.5770 & 18.5770 & 538300 & 2 & 640 & 0.0000 & $4 d 34$ & 4f 44 & 3788660 & 4326960 & \\
\hline 18.6134 & 18.6166 & 537155 & $1 b$ & 43 & 0.0032 & 4 p 12 & $4 d 12$ & 3181814 & 3719060 & \\
\hline 18.6290 & 18.6290 & 536797 & $3 b$ & 894 & 0.0000 & $4 d 43$ & 4f 53 & 3777140 & 4313940 & \\
\hline 18.6451 & 18.6451 & 536334 & 4 & 747 & 0.0000 & $4 d 42$ & 4f 52 & 3738070 & 4274400 & \\
\hline 18.6599 & 18.6599 & 535909 & 4 & 1060 & 0.0000 & $4 \mathrm{~d} 51$ & 4f 61 & 3719430 & 4255340 & \\
\hline 18.7319 & 18.7341 & 533786 & $1 \mathrm{~b}$ & 64 & 0.0022 & $4 d 32$ & 4f 31 & 3732080 & 4265930 & $\mathrm{q}$ \\
\hline 18.7441 & 18.7415 & 533575 & $2 b$ & 83 & -0.0026 & 4d 34 & 4f 33 & 3788660 & 4322160 & \\
\hline 18.7753 & 18.7719 & 532711 & 7 & 705 & -0.0034 & $4 d 5 / 2$ & 4f $7 / 2$ & 904224 & 1436839 & AgXIX 18.7753 \\
\hline 18.7995 & 18.8046 & 531786 & 2 & 205 & -0.0051 & $4 p 13$ & $4 d 24$ & 3251230 & 3783160 & blend $\mathrm{AgXIX} 18.8073$ \\
\hline 18.8352 & 18.8368 & 530876 & 2 & 82 & 0.0016 & $4 \mathrm{p} 12$ & $4 d 22$ & 3206188 & 3737110 & \\
\hline 18.8605 & 18.8626 & 530150 & 4 & 271 & 0.0021 & 4 p 23 & $4 d 32$ & 3201870 & 3732080 & Tentative, Blend \\
\hline 18.8654 & 18.8626 & 530150 & 4 & 405 & -0.0028 & 4 p 24 & $4 d 34$ & 3258589 & 3788660 & Tentative, Blend \\
\hline 18.9092 & $18.9092 \mathrm{a}$ & 528843 & $7 \mathrm{c}$ & 693 & 0.0000 & $4 \mathrm{p} 33$ & $4 d 43$ & 3248295 & 3777140 & \\
\hline 18.9315 & $18.9315 \mathrm{a}$ & 528220 & $7 \mathrm{c}$ & 851 & 0.0000 & $4 \mathrm{p} 41$ & 4d 51 & 3191211 & 3719430 & \\
\hline 18.9330 & $18.9230 \mathrm{a}$ & 528457 & $7 \mathrm{c}$ & 496 & -0.0100 & 4 p 32 & $4 d 42$ & 3209891 & 3738070 & \\
\hline 18.9674 & 18.9704 & 527137 & 4 & 15 & 0.0030 & 4 p 32 & $4 d 22$ & 3209891 & 3737110 & $\mathrm{~S}$ \\
\hline 19.0632 & 19.0519 & 524882 & 8 & 147 & -0.0112 & 4 p 24 & 4d 24 & 3258589 & 3783160 & blend AgXIX 19.0543 \\
\hline 19.1502 & 19.1501 & 522190 & 2 & 159 & 0.0000 & 4 p 32 & $4 d 32$ & 3209891 & 3732080 & \\
\hline 19.4980 & 19.4956 & 512936 & 5 & 103 & -0.0024 & $4 \mathrm{p} 12$ & $4 d 12$ & 3206188 & 3719060 & blend AgXIX 19.4981 \\
\hline 19.5427 & 19.5420 & 511718 & 1 & 98 & -0.0007 & 4 p 32 & $4 d 31$ & 3209891 & 3721590 & \\
\hline
\end{tabular}

Notes: $\quad$ a Wavelength from ref [11]. The present spectra lead to an unresolved peak with global intensity 7

$\mathrm{S}$ line is too strong with regard to the gA value

$\mathrm{S}, \mathrm{Ag}$ XXI This Ag XX transition is probably masked by a AgXXI transition.

blend Ag XIX blend with a classified line of Cu-like Ag XIX with wavelength from [13].

Ag XIX AgXIX lines with wavelengths from [13].

$\mathrm{q}$ this line did not appear in all spectra

b broad line

c only combined intensity can be assigned for all three transitions 
the changes in leading components are small in those close elements.

\section{Conclusions}

A highly ionized silver plasma generated by a fast high current capillary discharge was used to identify forty-three transitions of Ni-like Ag. The average deviation between the measured and theoretical GLS transition wavelength values is $0.0026 \mathrm{~nm}$. The newly identified lines can be of use in the plasma diagnostic necessary to optimize the performance of Ni-like Ag lasers operating at $13.9 \mathrm{~nm}$.

\section{Acknowledgments}

This work was supported by DARPA grant G-DAAD 19-99-1-0279 and by the National Science Foundation. The Laboratoire Aimé Cotton is associated with the University Paris-Sud. We also would like to thank Eric Hammarsten for his assistance with the experiment and acknowledge an equipment grant from the W. M. Keck foundation to Colorado State University.

\section{References}

1. Rocca, J. J. et al., Phys. Rev. Lett. 73, 2192 (1994).
2. Tomasel, F. G., Rocca, J. J., Shlyaptsev, V. N. and Macchietto, C. D., Phys. Rev. A 55, 1437 (1997).

3. Frati, M., Seminario, M. and Rocca, J. J., Opt. Lett. 25, 1022 (2000).

4. Attwood, D. T., "Soft X-rays and Extreme Ultraviolet Radiation" (Cambridge University Press, 1999).

5. Li, Y. et al., Phys. Rev. A 58, 2668 (1998).

6. Zhang, J. et al., Phys. Rev. Lett. 78, 3856 (1997).

7. Warwick, P. et al., IEEE J. Selected Topics Quantum Electron. 5, 1447 (1999).

8. Dunn, J. et al., Phys. Rev. Lett. 84, 4834 (2000).

9. Klisnick, A. et al., J. Opt. Soc. Am. B 17, 1093 (2000).

10. Kuba, J. et al., Phys. Rev. A 62, 043808 (2000).

11. Rahman, A., Hammarsten, E. C., Sakadzic, S., Rocca, J. J. and Wyart, J.-F., Physica Scripta 67, 414 (2003).

12. Churilov, S. S., Ryabstev, A. N. and Wyart, J.-F., Physica Scripta 38, 326 (1988).

13. Reader, J., Acquista, N. and Cooper, D. N., J. Opt. Soc. Am. 73, 1765 (1983).

14. Gonzalez, J. J., Frati, M., Rocca, J. J., Shlyaptsev, V. N. and Osterheld, A., Phys. Rev. E. 65, 026404 (2002).

15. Rahman, A. et al., P 113 "X-ray Lasers 2002", AIP Conf. Proceed. 641 (Edited by J. J. Rocca, J. Dunn and S. Suckewer), (2002).

16. Kelly, R. L. and Palumbo, L. J., "Atomic and Ionic Emission Lines Below 2000 Angstroms," NRL Report 7599 (1973).

17. Cowan, R. D., "The Theory of Atomic Structure and Spectra," (University of Calif. Press, Berkeley 1981) and computer codes. 